\title{
EFFECT OF MORPHOLOGICAL CHANGES AND WAVES ON SALINITY INTRUSION IN THE NANAKITA RIVER MOUTH
}

\author{
Nguyen Trung VIET ${ }^{1}$, Hitoshi TANAKA ${ }^{2}$, Daisuke NAKAYAMA ${ }^{3}$ and Hiroto YAMAJI ${ }^{4}$ \\ ${ }^{1}$ Student Member of JSCE, Doctoral Student, Department of Civil Engineering, Tohoku University \\ (6-6-06 Aoba, Sendai 980-8579, Japan) \\ ${ }^{2}$ Fellow Member of JSCE, Dr. of Eng., Professor, Department of Civil Engineering, Tohoku University \\ ${ }^{3}$ Student Member of JSCE, Master Student, Department of Civil Engineering, Tohoku University \\ ${ }^{4}$ Member of JSCE, Research Associate, Department of Civil Engineering, Tohoku University
}

\begin{abstract}
Salinity intrusion into estuaries, in general, is mostly affected by river water discharge and tidal level. In addition, the change of salinity can also be influenced by other external forces such as wave height, river mouth morphology. However, there has been none of the study considering this kind of aspect. In fact, the rapid change of river mouth morphology can strongly effect on salinity distribution. Hereby, we carried out the study at the Nanakita river mouth for considering the effect of morphology and wave height. One maneuver to escape the situation of lacking in morphology data is to use the digital camera for taking and collecting oblique photographs. Once this technique is utilized, the highly frequent morphological data can be obtained. These data are useful to the simulation of salinity intrusion into the river mouth with a short time interval. Furthermore, effectiveness of each external force also will be examined by sensitivity analysis .
\end{abstract}

Keywords: Nanakita river mouth, morphology change, sensitivity analysis, salinity intrusion

\section{INTRODUCTION}

Estuary is the connection place between river and sea. Circulation and exchange of fresh-saline water, substance even as sediment induced the complication of environment, ecological system and morphology of the estuary. Especially, in tideland area, species of organism and the improvement of water purification are being paid more attention. In the maintenance of river mouth and water utilization, salinity intrusion is a big issue.

In general, salinity intrusion into estuaries is mostly affected by river discharge and tidal level. Besides, the change of salinity can also be influenced by other external forces such as wave height, river mouth morphology. However, there has been none of the study considering this kind of aspect.

Presently, we carried out study at the Nanakita river mouth considering the effect of morphology and wave height. The river mouth morphology has been changed rapidly, which may strongly effect on salinity. By and large, data accumulation of river mouth topography at a short time interval is very rare, whereas field data of salinity $(S)$ variation in a river mouth can now be easily obtained by using the instruments, which can measure the conductivity that can then be converted to the parameters of salinity and temperature. Even though we have detailed data sets of salinity in the river mouth at both near the surface and bottom layer, it is quite difficult to correlate them with river mouth morphology due to the lack of corresponding field surveying data of river mouth topography, caused by inconsistency of data acquisition time variation of salinity concentration and river mouth morphology. This is one of the reasons why quantitative relationship between the intrusion of salinity and river mouth morphology has not been thoroughly clarified yet. One maneuver to escape the situation of lacking morphology data is to use a modern technology known as digital camera for taking oblique photographs. Hereby, instead of surveying river mouth morphology, oblique photographs are utilized to investigate the quantitative relationship between salinity concentration and river mouth morphology.

Recently, Artificial Neural Network (ANN) model has been widely applied in forecasting natural phenomena such as time variation of rainfall, river 


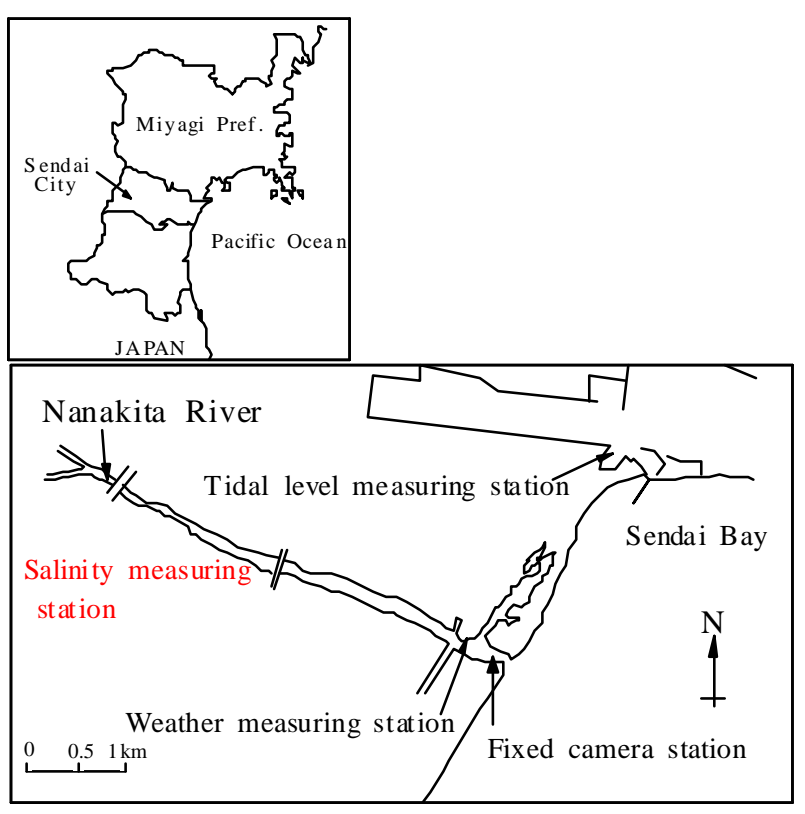

Fig. 1 Location map of the Nanakita river mouth

flood, tidal level, water level, salinity concentration, shoreline changes etc.

Supharatid ${ }^{1,2)}$ showed that lead time of 1 to 24 hourly tidal levels can be predicted successfully using only a short time hourly learning data and the results show a considerably better performance of NN model over the conventional models. Huang and Foo $^{3)}$ use ANN model to successfully predict the variation of salinity in Apalachicola river by both gradient and conjugated decent method.

Therefore, the purpose of this paper is to consider the effect of morphological changes and waves on characteristics of salinity intrusion into the Nanakita river mouth by the use of ANN model.

\section{AREA DISCRIPTIONS}

The Nanakita river mouth is selected as the study area. The Nanakita river originates from the northern part of Sendai City in Miyagi Prefecture and goes through the Sendai Bay as seen in Fig. 1. The catchment area and the length of this river are $229 \mathrm{~km}^{2}$ and $45 \mathrm{~km}$ respectively. Tidal range at the Nanakita river estuary is about $150 \mathrm{~cm}$ at spring tide while the flood discharge of the 100-year return period is $1,650 \mathrm{~m}^{3} / \mathrm{s}$ and the typically river discharge is $10 \mathrm{~m}^{3} / \mathrm{s}$. There is a jetty on the left-hand side of the river mouth, which limits the migration of the mouth to the north direction, whereas the movement in the south is not limited. During winter season, the river mouth often closes due to small river discharge. The complete closures of the river mouth were observed in 1988 and 1994. According to the remarkable river mouth topographical changes, it effects to flood problem in the low land area and the

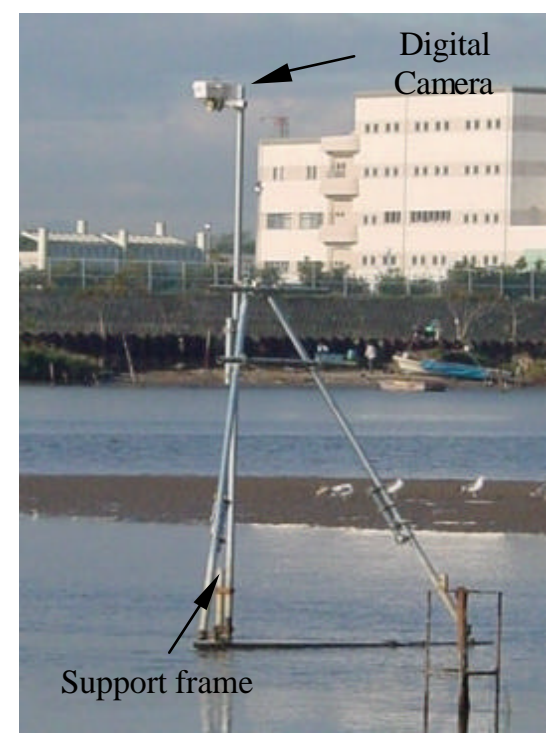

Photo 1 Fixed camera station

environment in the Gamo lagoon, where is well known as wild birds, the Teizan canal and many precious historic waterfront area.

Consequently, a particular study area as Nanakita river mouth is suitable for studying the influence of morphological changes and wave motions on salinity variation.

\section{OBSERVATION DATA}

The acquisition method and details of data collection used in the present paper are shown as follows (see Fig. 1)

\section{(1) Time variation of salinity}

Observation point is located about $3 \mathrm{~km}$ from the Nanakita river mouth in upstream. Salinometer (Alec Electronic Ltd., MDS-T) is fixed from the river bed in two points $(80 \mathrm{~cm}$ and $30 \mathrm{~cm}$ from the river bed). Time interval of salinity and water temperature collecting is 10 minute. The data of the upper point ( $80 \mathrm{~cm}$ from the river bed) is used in this study because the salinometer in the upper layer is sensitive to the salinity changes.

\section{(2) Wind velocity ( $V$ )}

As usual, weather meter (DAVIS, weather monitor II) is installed at the point $0.5 \mathrm{~km}$ from the river mouth. However, from July to September 2005, this meter was broken. Therefore, wind data in this period is collected at Sendai Port, which is $2 \mathrm{~km}$ far from the Nanakita river mouth.

\section{(3) Morphology data}

The digital camera was set up in fixed camera station shown in Fig. 1, which is far from the river entrance about $200 \mathrm{~m}$, and with $4 \mathrm{~m}$ height as seen in 


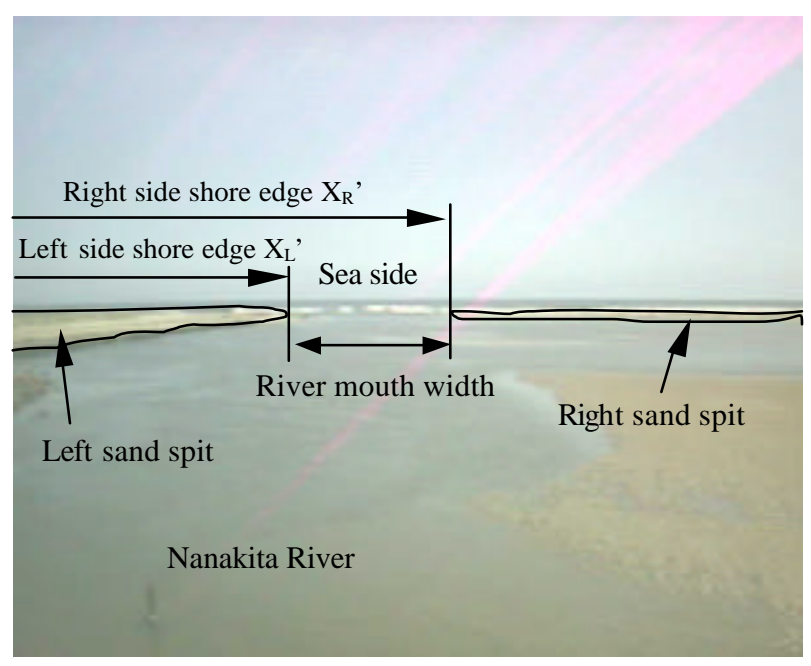

Photo 2 An example of oblique photograph

Photo 1. The time interval of taking photo is one hour. The direction of the camera turns to the sea side, which takes into account to the width of the head of the Nanakita river mouth.

The above example of oblique photo taken on $29^{\text {th }}$ July 2005 is shown in Photo 2. The technique of analysis of the morphological data can be summarized as follows:

The points of the left shore edge and the right shore edge are defined based on the left end of the screen as coordinates $X_{L}{ }^{\prime}, X_{R}{ }^{\prime}$. The width of the right side shore edge and the left shore edge at each time is assumed $B^{\prime}$. This width $B^{\prime}$ is assumed to be an index of the river mouth width. In addition, from the distance in coordinates on the screen defined preceded, it is mended the distance into a real scale. Hereafter, two target points are installed on the photograph, the distance between them is assumed to be $10 \mathrm{~m}$. At the taken image, by requesting the distance on the screen and calculating of the ratio to an actual distance, river mouth width from the left edge to the right edge is calculated. Moreover, because the tidal kvel varies frequently during the time when the photograph was taken, it is necessary to correct due to this parameter. Here, he river mouth width at T.P. $0 \mathrm{~m}$ is requested. Via the value of slope inclination, $I$, which is obtained from the results of the topographic survey of five times, the correction value will be gained. Slope inclination $I$ is equal to 0.057 if tidal level is greater than T.P.0m, it becomes 0.164 if tidal level is less than T.P. $0 \mathrm{~m}$. Hence, amount of river mouth width correction, $\Delta X$, is obtained by following expression as:

$$
\Delta X=-\Delta H / I
$$

In which, $\Delta H$ is water level (T.P.0 m). As a result, corrected actual width $(B)$ of the head of river mouth. The left shore edge $X_{L}$ and the right shore edge $X_{R}$ are obtained.
By making a comparison between the results of river mouth width of this method with that of field measurement and aerophotograph analysis method, it is indicated that the results are almost the same. By means of using present method, it is shown that the use of digital photos is effective to observe river mouth morphology and satisfactory accuracy can be obtained $^{4}$.

\section{(4) Tide, wave, and river discharge}

Wave heights $(H)$ are obtained at the offshore wave station near the Sendai Port. The river discharge $(Q)$ is measured at a gauging station $9 \mathrm{~km}$ upstream. Tidal level $(\eta)$ is measured every one hour at the Sendai Port. These data are collected from related organizations.

\section{STUDY METHOD}

\section{(1) Back propagation network}

Back propagation (BP) network was developed by Rumelhart et al. ${ }^{5)}$. The multiple-layer perceptron was used in the learning process between input and output patterns. The BP network is based on a supervised learning technique that compares the computed output to the target output and then readjust the weights backward in the network. The same input is presented to the network for the next time, therefore the computed output will be closer to the target output ${ }^{6}$. . In ANN model, the weights are adjusted to obtain the desired results. This process is called learning or training. After the learning process, the weights are frozen. A data set that the ANN has not used before is presented to verify its performance, namely verification process.

\section{(2) Input data}

Before simulating of salinity changes, we should select external forces affecting the changes of salinity. These external forces are main input data, namely, river discharge, tidal level and velocity of wind.

In order to improve the accuracy, in the present study, we consider two more parameters, which may affect the changes of salinity: wave height and morphology change of river mouth, that is represented by river mouth width.

In this study, to assess accuracy of computation, efficient index $(E I)$ and root mean square error (RMSE) were used. If $E I$ reaches $100 \%$ and $R M S E$ reaches 0 , a perfect correlation between observation and model result is obtained.

\section{RESULTS AND DISCUSSIONS}




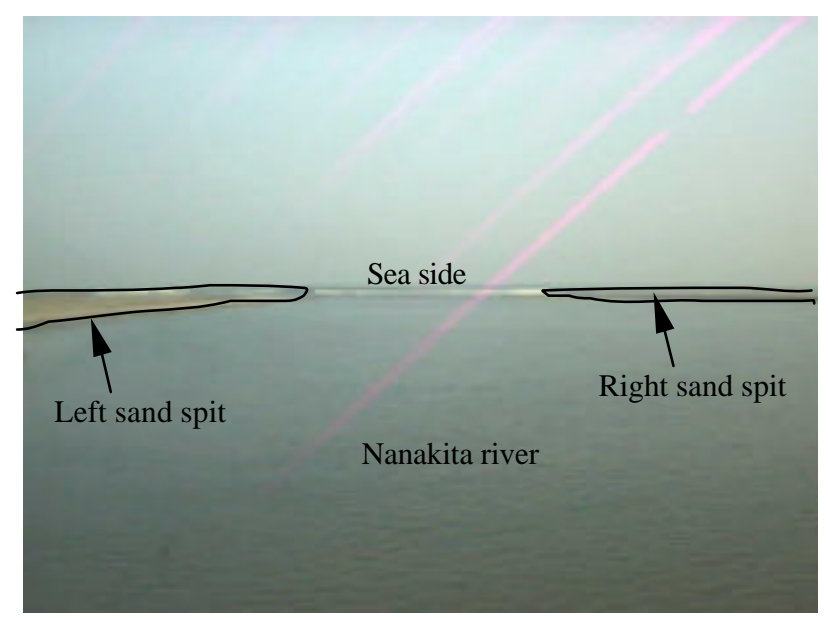

Photo 3 Image of river mouth taken on $18^{\text {th }}$ July 2005

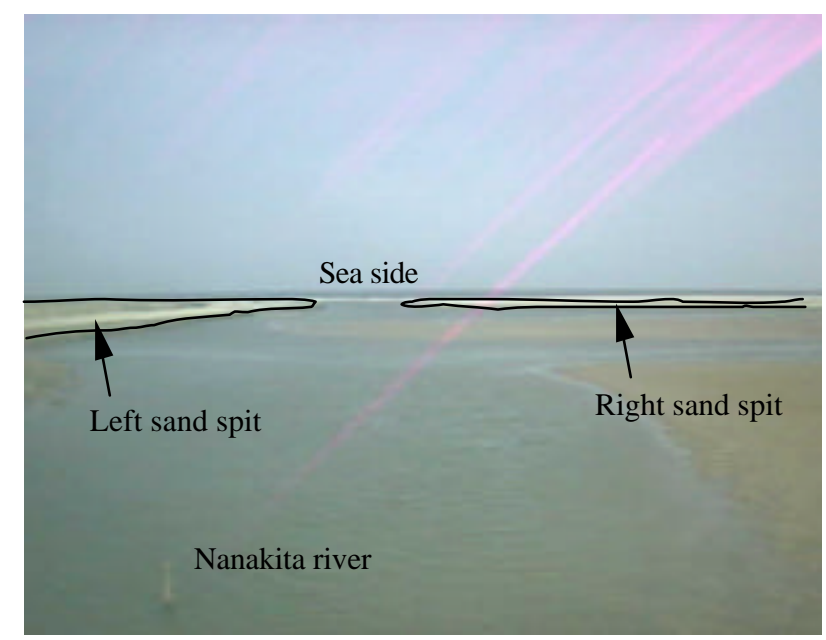

Photo 4 Image of river mouth taken on $14^{\text {th }}$ August 2005

(1) Distinct morphological change of river mouth By seeing the following photographs taken at the fixed camera station, a distinct morphological change of the head of the Nanakita river mouth was observed.

Photo 3 was taken on $18^{\text {th }}$ July 2005 with a very large river mouth width, while photo 4 was taken on $14^{\text {th }}$ August 2005 with a small river mouth width. Within only one month, the river mouth width decreased by almost 50\%. Thus, these morphological changes are supposed to influence on the changing salinity intrusion into the river.

Regarding to Tanaka and Lee ${ }^{7)}$, in the Nanakita river mouth, a special phenomenon should be noted that there is an increased water level at the river mouth relating to wave height, that is caused by wave set-up due to wave-breaking.

According to raise of water level in the Nanakita river mouth, as a result, more additional tidal prism is penetrated to exacerbate the seawater through the upstream. Importantly, the more water level increased, as a result, the more salinity intruded into the river.
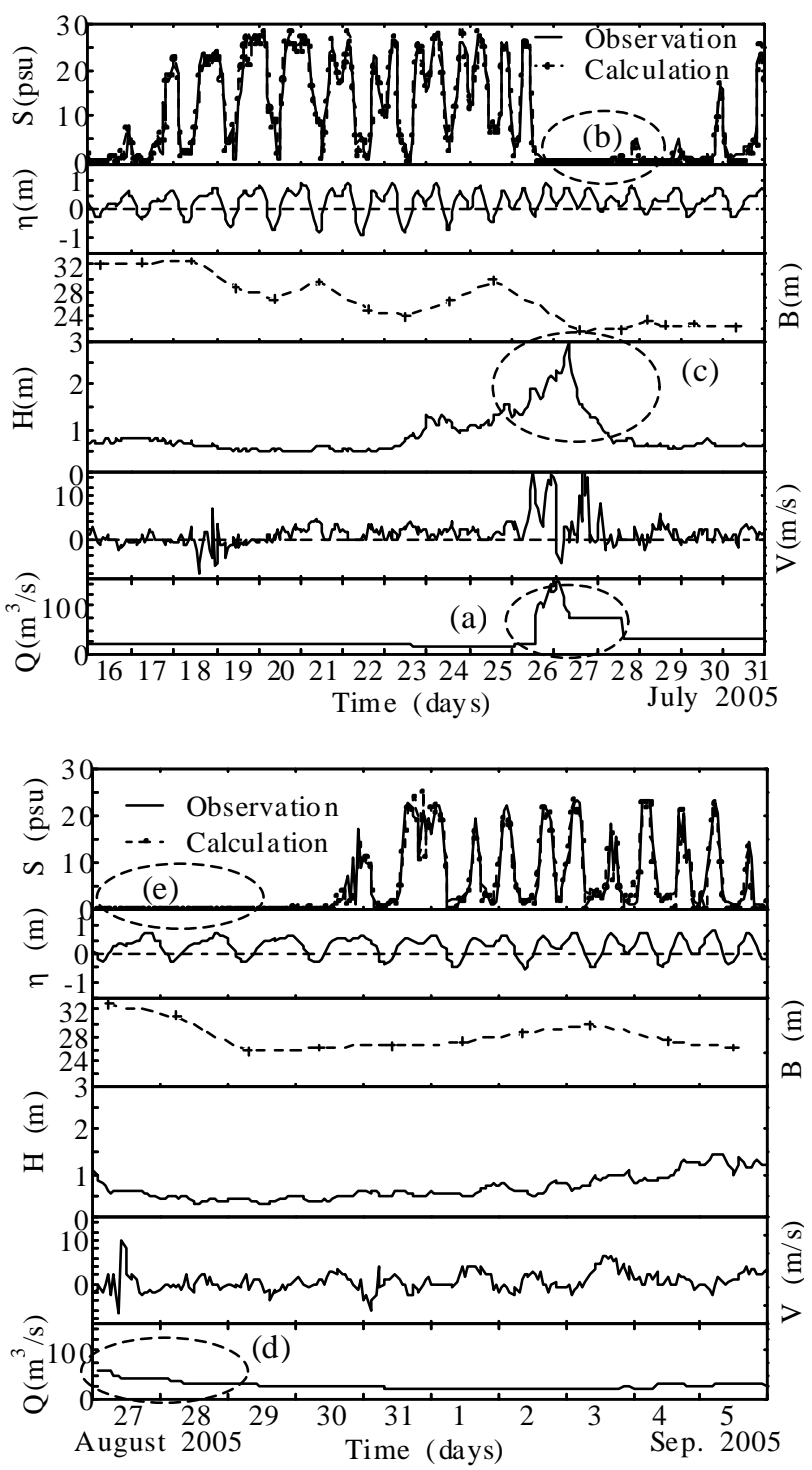

Fig. 2 Quantitative correlation between parameters

Fig. 2 shows a quantitative correlation between parameters during the period of $16^{\text {th }}-31^{\text {st }}$ July and $27^{\text {th }}$ August to $5^{\text {th }}$ September 2005. In Fig. 2, during flood period as shown in (a) and (d), a large amount of freshwater discharge can spread out and dominate saline water. The strong current can also enlarge the river mouth width. It can be seen that, if discharge is greater than $50 \mathrm{~m}^{3} / \mathrm{s}$, the salinity concentration will become almost zero, denoted in (b) and (e). In that period, the discharge becomes predominant.

During flood period, the wave hight also was very high, as seen in (c). However, due to the predominance of river discharge, effect of wave height on the salinity is not so distinct.

After flood period the discharge kept almost constant. The salt water, which moved underneath and pushed back to upstream, was created starting recovery of salinity. It should be noted that, the river mouth width has increased from $29^{\text {th }}$ August to $3^{\text {rd }}$ September. 
Table 1 Simulation results for different periods

\begin{tabular}{|c|c|c|c|c|}
\hline $\mathrm{N}_{\mathrm{o}}$ & Date & $\begin{array}{c}\text { Averaged } \\
\text { salinity } \\
(\mathrm{psu})\end{array}$ & $\begin{array}{c}\mathrm{EI} \\
(\%)\end{array}$ & $\begin{array}{c}\text { RMSE } \\
(\mathrm{psu})\end{array}$ \\
\hline 1 & $16 / 07 \sim 31 / 07 / 05$ & 9.59 & 97.59 & 1.47 \\
\hline 2 & $01 / 08 \sim 10 / 08 / 05$ & 12.87 & 96.67 & 1.74 \\
\hline 3 & $27 / 08 / \sim 05 / 09 / 05$ & 5.54 & 95.97 & 1.50 \\
\hline 4 & $06 / 09 / \sim 15 / 09 / 05$ & 7.59 & 96.40 & 1.68 \\
\hline
\end{tabular}

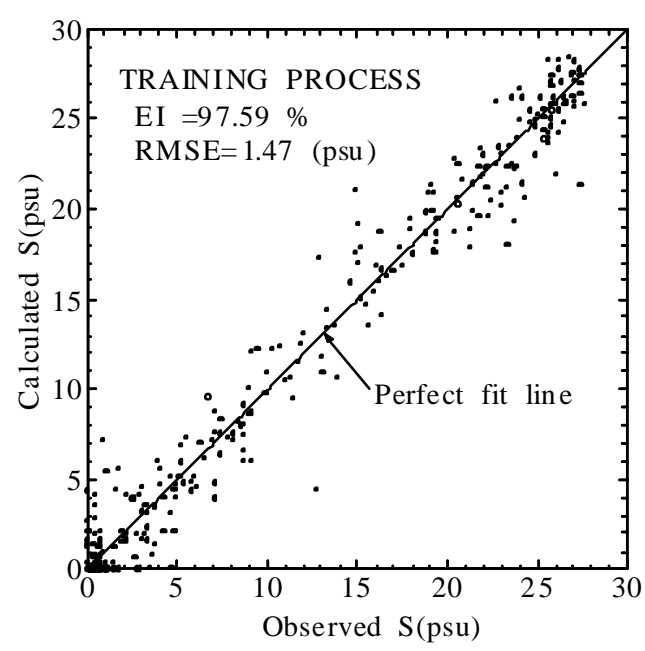

Fig. 3 Simulation results from 16-31 July 2005

In addition, there has been a simultaneously increased wave height. This combination also lead to more salinity intrusion into the river.

\section{(2) Simulation results}

The network structure $I_{5} H_{15} O_{1}$ (5 neurons in input layer, 15 neurons in hidden layer and 1 neuron in output layer) was used in the learning process to simulate the salinity in the Nanakita river mouth.

Using different number of input data as mentioned in 4(2), it also can be found that the most appropriate number of input data are five inputs.

The training processes, In Table 1, were done separately, because the better results can be obtained After finishing training processes, the verification has been done for sensitivity analysis.

According to one data set, for the period of $16^{\text {th }}$ to $31^{\text {st }}$ July 2005 , the simulation result can be well withdrawn by $E I=97.59 \%$ and $R M S E=1.47 \mathrm{psu}$. Both Fig. 2 and Fig. 3 illustrate that a successful correlation between observed data and calculated result is obtained.

\section{(3) Sensitivity analysis}

A sensitivity analysis is the process of varying model input parameters over a reasonable range and observing the relative change in model response. Sensitivity analysis measures the impact on project outcomes of changing one or more key input values about which there is uncertainty. Sensitivity analysis Sensitivity analysis measures the impact on project

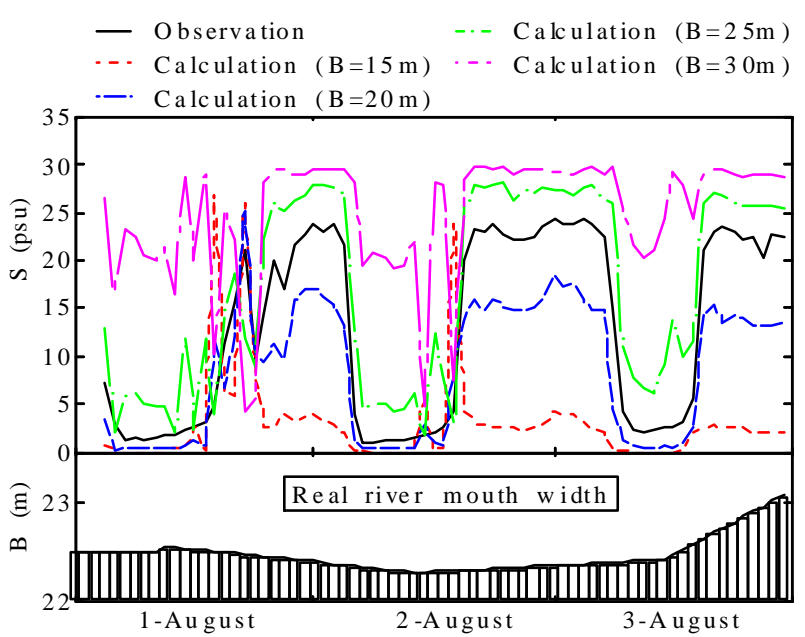

Fig. 4 Time variation between observation and hypothetical input data

outcomes of changing one or more key input values about which there is uncertainty. Sensitivity analysis can also be represented on different combinations of input values, that is, several variables are altered at once and then a measure of worth is computed.

In this study, two sensitivity tests are conducted to determine the effect of morphological changes and the combination of two external forces on the salinity distribution in the Nanakita river mouth.

Hypothetical input data of river mouth width, and wave height selected as $B(10 \mathrm{~m}, 15 \mathrm{~m}, 20 \mathrm{~m}$, $25 \mathrm{~m}, 30 \mathrm{~m}, 35 \mathrm{~m}), H(0.25 \mathrm{~m}, 0.5 \mathrm{~m}, 0.75 \mathrm{~m}, 1.0 \mathrm{~m}$, $1.25 \mathrm{~m}, 1.5 \mathrm{~m})$ respectively, are used to make sensitivity analysis. The following, $S / \bar{S}$, is drawn to see to what extent, and which factor is predominant for salinity; where, $\mathrm{S}$ is the average of observation data, $\bar{S}$ is the average of calculation result.

Due to the river water discharge is almost constant during the period of $1^{\text {st }}-3^{\text {rd }}$ August 2005, therefore, this period is selected as a data set for the sensitivity analysis.

\section{(a) Effect of river mouth width}

Figure 4 reveals the time variation between observation and hypothetical input data. In Fig. 4, real time variation of salinity (upper part) and river mouth width (lower part) is plotted using black color, whereas, hypothetical river mouth width is plotted using colored lines (upper part) including $20 \mathrm{~m}, 25 \mathrm{~m}, 30 \mathrm{~m}, 35 \mathrm{~m}$, respectively. It is clearly seen that, there is a distinctly increasing time variation of salinity due to the increase of river mouth width.

Figure 5 depicts the relationship between river mouth width and average of salinity. It can be found that the correlation between river mouth width and salinity is directly proportional Hence, we can not ignore the effect of river mouth morphology when simulating salinity. 


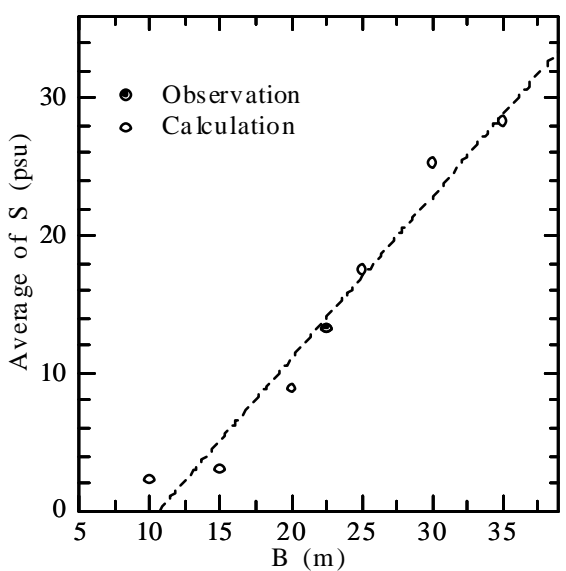

Fig. 5 Averaged salinity and river mouth width
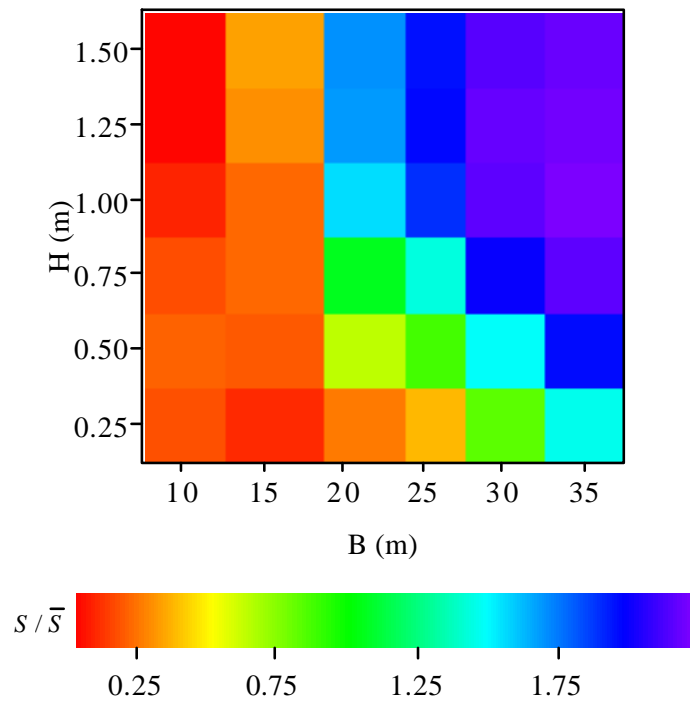

Fig. 6 Relation of salinity due to morphological change of river mouth and wave height

Using different data sets for sensitivity analysis, the similar tendency of results can be obtained as compared with data set from $1^{\text {st }}$ to $3^{\text {rd }}$ August 2005.

(b) Effect of two combined external forces: $B$ and $H$

It was tried to express the salinity distribution by analyzing the effect of two simultaneous external forces: river mouth width with wave height.

From Fig. 6, it can be seen that, the increased river mouth width, the more salinity intruded into the upstream. It is understood that the influence of morphological change is significantly larger than wave height during the period above mentioned.

In general, the wider river mouth width, the more salinity intruded into the upstream because it facilitates sea water to push further back to upstream Furthermore, at a relatively bigger river mouth, wave set-up cannot be observed in the river entrance whereas at smaller river mouths, distinct water level rise above tidal elevation can be observed during the period of high waves ${ }^{8}$. This is due to its shallow water depth at the river mouth. Consequently, the water level rise leads to the enhancement of salinity intrusion into the river. It should be noted that, the large-scale and small-scale river also lead to the different salt water incursion into the river.

\section{CONCLUSIONS}

This paper applied an artificial neural network model to address the problems of simulation of salinity concentration in the Nanakita river mouth. A very good correlation between external forces with salinity concentration is built.

By the use of ANN model, a quantitative salinity concentration correlated with parameters of external forces is determined. The morphological changes of the head of the river mouth strongly influenced on the salinity distribution in the Nanakita river mouth.

In addition, based on the changes of two combined external forces, it can also be concluded that morphological change is predominant as compared with wave height.

ACKNOWLEDGEMENTS: A part of this study was financially supported by a Project on "Development of Risk Management System for the Safety of Water Resources in Monsoon Asia" (RR 2002) from the Ministry of Education, Science and Culture, Japan. Their acknowledgements should be extended to the Foundation of River and Watershed Environment Management for their support.

\section{REFERENCES}

1) Supharatid, S.: Application of a neural network model in establishing a stage-discharge relationship for a tidal river. Hydrological Processes, 17, 3085-3099, 2003.

2) Supharatid, S.: Field data recovery of tidal level using a neuro-genetic algorithm. Coastal Engineering Journal, Vol. 46, No. 4, 369-383, 2004.

3) Huang, W. and Foo, S. : Neural network modelling of salinity variation in Apalachicola River. Water Research, 36, 256-361, 2002.

4) Margery, F.O. and John, S.F.: Shoreline analysis using digital photogrammetry. Proceedings of $25^{\text {th }}$ International Conference on Coastal Engineering ASCE, 3750-3756, 1996.

5) Rumelhart, D.E., Hinton, G.E., and Williams, R.J.: Learning Internal Representations by Error Propagation, in Rumelhart, D.E., McCelland, Parrallel Distributed Processing, Explorations in the Microstructure of Cognition, Vol. 1, the MIT Press, 1986. 6) Blum, A.: Neural Networks in C++: An Object-Oriented Framework for Building Connectionist Systems. New YorkWiley, 1992.

7) Tanaka, H., Lee, H.: Influence of Jetty Construction on Morphology and Wave Set-up at a River Mouth. Coastal Engineering Journal, Vol. 45, No4, 659-683

8) Tanaka, H., Nagabayashi, H. and Yamauchi, K.: Observation of Wave Set-up Height in a River Mouth. Proceedings of $27^{\text {th }}$ International Conference on Coastal Engineering,, 3458-3471, 2000.

(Received September 30,2005) 